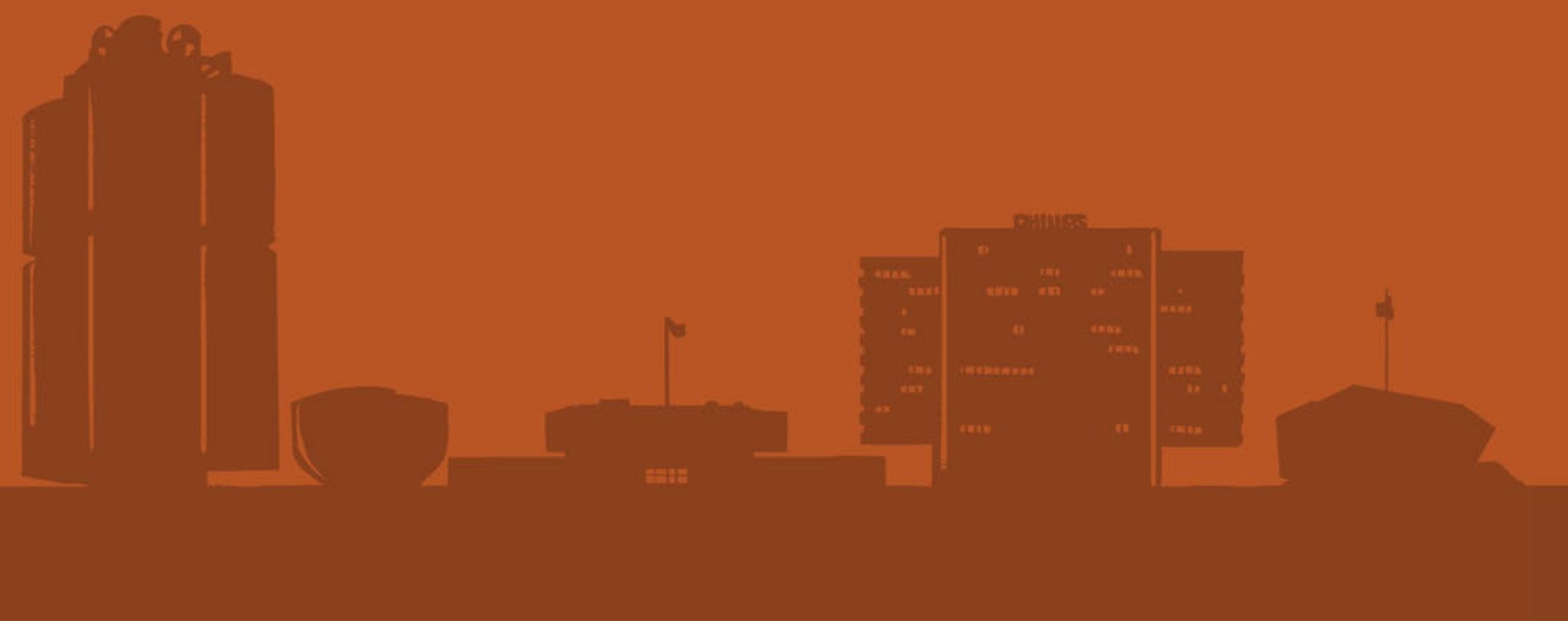




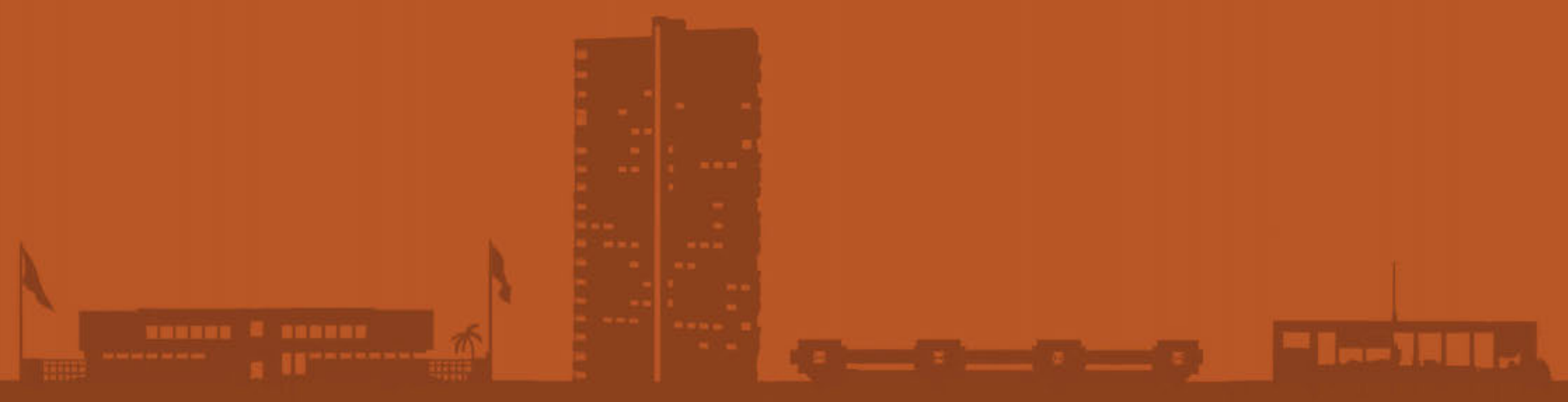




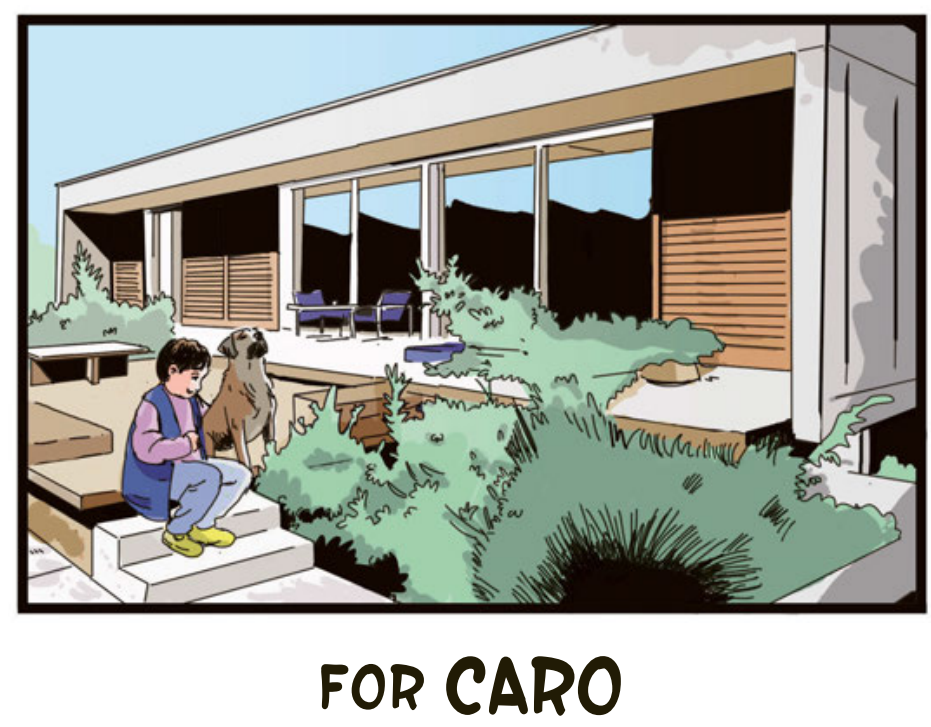





\section{BENJAMIN SWICZINSKY}

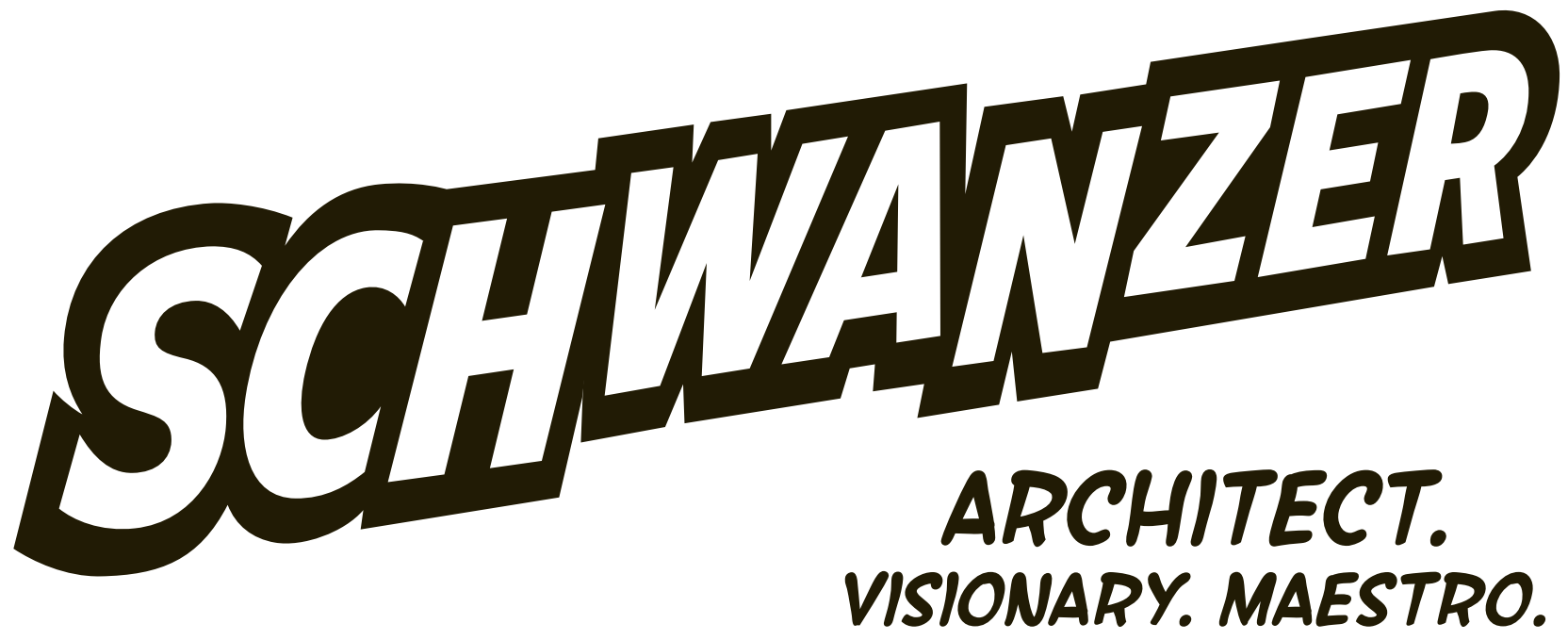

Three Decades of Architectural and Contemporary History

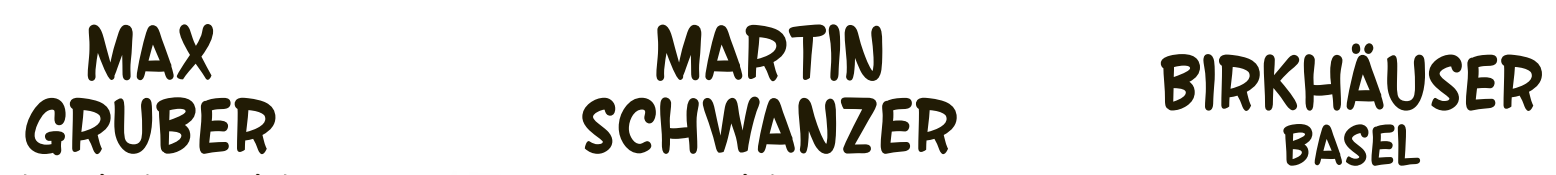

Text and Story Editing

Editor

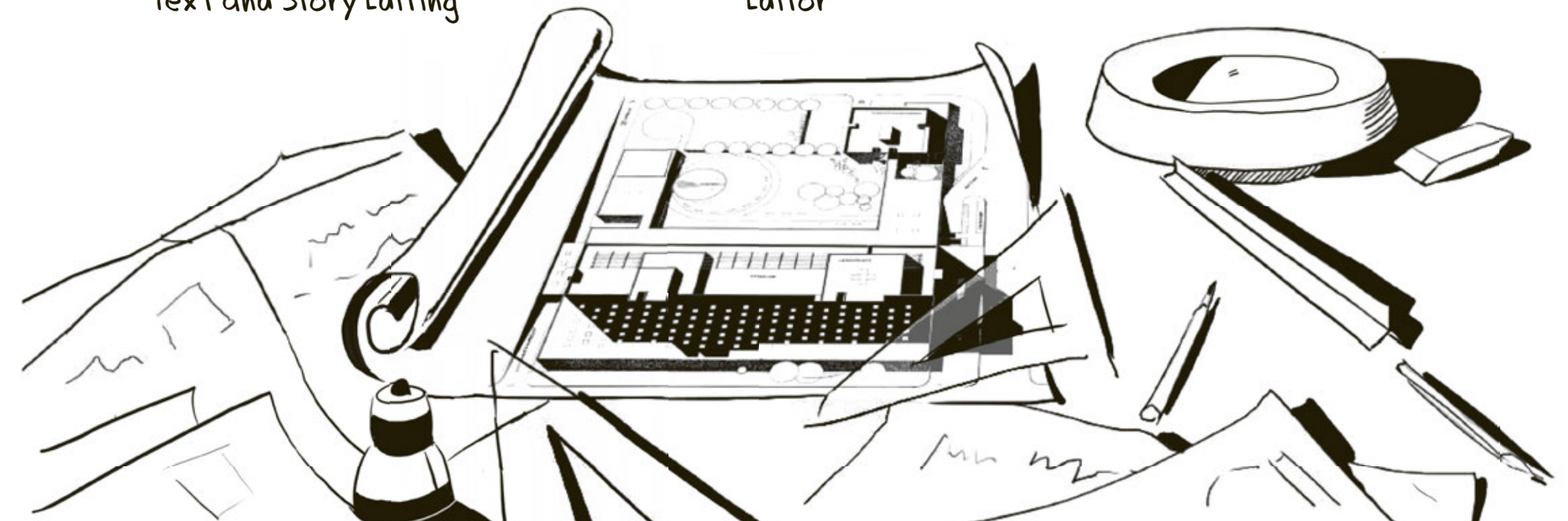


